\title{
Population genetic analyses of susceptibility to increased body weight
}

Dejan Nikolic', Suzana Cvjeticaninn ${ }^{2,3}$, Ivana Petronic ${ }^{1,2}$, Zeljka Milincic², Radivoj Brdar2,4, Radmila Karan ${ }^{5}$, Ljubica Konstantinovic ${ }^{2,6}$, Aleksandra Dragin ${ }^{2,6}$, Milisav Cutovic ${ }^{2,6}$

1Physical Medicine and Rehabilitation Department, University Children's Hospital, Belgrade, Serbia

${ }^{2}$ Faculty of Medicine, University of Belgrade, Serbia

IInstitute for Human Genetics, Faculty of Medicine, Belgrade, Serbia

4Pediatric Surgery Department, University Children's Hospital, Belgrade, Serbia

${ }^{5}$ Cardiac Surgery Clinic, Clinical Centre of Serbia, Belgrade, Serbia

${ }^{6}$ Clinic for Rehabilitation, School of Medicine, Belgrade, Serbia

Submitted: 31 December 2010

Accepted: 24 April 2011

Arch Med Sci 2012; 8, 6: 998-1002

DOI: 10.5114/aoms.2012.32405

Copyright $@ 2012$ Termedia \& Banach

\begin{abstract}
Introduction: Obesity is a complex condition with multifactorial origin. Assuming that such a state is genetically controlled, the aim of our study was to evaluate the degree of genetic homozygosity among overweight and obese individuals by the homozygously recessive characteristics (HRC) test.

Material and methods: We analysed the presence, distribution and individual combination of 15 selected genetically controlled recessive phenotype traits in a sample of 140 individuals with increased body mass index (overweight individuals $n=100$ and obese individuals $n=40$ ) and a control group of normal weight individuals $(n=300)$.

Results: Obese individuals have significantly higher mean values for genetic homozygosity than those with normal weight (normal weight: $3.61 \pm 1.48$; obese: $4.13 \pm 1.47, p<0.05$ ) and difference in the presence of certain individual combinations of evaluated phenotype traits $\left(\Sigma \chi^{2}=76.9 ; p<0.01\right)$. There was no difference in average homozygosity of such genetic markers between groups of normal weight and overweight individuals (normal weight: $3.61 \pm 1.48$; overweight: $3.93 \pm 1.51, p>0.05$ ) and between groups of overweight and obese individuals (overweight: $3.93 \pm 1.51$; obese: $4.13 \pm 1.47, p>0.05$ ). There is no difference in the presence of certain individual combinations of evaluated phenotype traits between overweight and obese individuals $\left(\Sigma \chi^{2}=20.6 ; p>0.05\right)$.

Conclusions: There is a populational genetic difference in the degree of genetic homozygosity and variability between the group of normal weight and group of obese individuals, indicating a possible genetic component. Overweight and obese individuals have a genetic predisposition, but different expression of genetic loads could be one of the possible explanations for different susceptibility to increase of fat mass and body mass index.
\end{abstract}

Key words: overweight, obesity, genetic variability, genetic homozygosity.

\section{Introduction}

Obesity is a complex condition with multifactorial origin and is highly prevalent in developed nations [1]. There are studies stressing that body mass index (BMI) as one of the obesity parameters is to a certain degree heritable [2]. On the other hand, observations from authors of several stud-

\author{
Corresponding author: \\ Dejan Nikolic MD, PhD \\ Physical Medicine \\ and Rehabilitation \\ Department \\ University Children's Hospital \\ 3 Nikole Stefanovica \\ 11000 Belgrade, Serbia \\ Phone: +381638133345 \\ E-mail: denikol27@yahoo.com
}


ies imply that a decline in physical activity in the group of adolescents leads to the development of obesity, as well as any disruption in the equilibrium of energy intake and energy expenditure $[3,4]$ Certain receptor polymorphisms [5], lifestyle [6, 7] and hypothalamic factors [8] reflect the complexity of overweight and obesity in the human population.

Since there are studies that address the possible role of heredity in the predisposition to overweight and obesity, we proposed the hypothesis that generally increased genetic homozygosity levels in samples of overweight and obese individuals could be population-genetic parameters for the prediction of such states.

It is very sensitive to estimate genetic homozygosity in human individuals, because only a small number of loci determining a specific morphophysiological character have been described so far. The recessive phenotype traits that are expressed under the influence of recessive genes constitute markers of the chromosomes for observed genes and markers of surrounding genes that could have some impact on susceptibility to obesity [9]. Increased genetic homozygosity has previously been described in several pathological conditions, indicating increased genetic loads in these groups of evaluated patients $[9,10]$.

Therefore, the aim of our study was to evaluate the degree of genetic homozygosity and genetic variability in overweight individuals and obese individuals.

\section{Material and methods}

\section{Study group}

In our study we evaluated 140 children and adolescents with increased body mass index. The evaluated population included individuals aged 10-18 years (mean: $14.53 \pm 2.85$ years). Participants were grouped into 3 groups: a group with normal body weight, an overweight group and an obese group. According to the recommendations from the World Health Organization (WHO), for children age 6-18 years, normal weight was described as BMI values between the $15^{\text {th }}$ and $85^{\text {th }}$ percentile for age and gender, overweight as BMI values between the $85^{\text {th }}$ and $95^{\text {th }}$ percentile, and obesity as BMI values above the $95^{\text {th }}$ percentile for age and gender [11]. Additionally, 300 individuals with normal weight were analysed as the control group.

Prior to inclusion in the study, all individuals (normal weight, overweight and obese) were completely assessed by a board certified paediatrician, physiatrist and paediatric surgeon in order to exclude other conditions that could influence BMI. All 3 groups of tested individuals (normal weight, overweight and obese) belong to the same ethnic group (Serbian population).

\section{Study material}

To establish BMI, participants' weight was measured in the morning before a meal in light clothes and height was measured as well. The degree of genetic homozygosity was assessed through the presence of 15 homozygous recessive characteristics (HRC) by the standardized HRC test that has been established for estimation of the proportion of homozygously recessive clearly expressed characteristics in every individual as markers of chromosomal homozygosities [12]. The presence of the studied genetically controlled recessive characteristics was used as a parameter for homozygosity of the corresponding genes and chromosomes.

Different frequencies of homozygously recessive characteristics in individuals of different groups being evaluated would be a manifestation of a kind of genetic load present in the selected samples of the studied population [13-16].

There were $10 \mathrm{HRC}$ in the region of the human head that were evaluated: unattached ear lobe (OMIM number 128900), continuous frontal hair line (OMIM number 194000), blue eyes (gene location 19p13.1-q13.11, OMIM number 227240), straight, soft and blond hair (OMIM numbers 139450 and 210750), double hair whorl, opposite hair whorl orientation (OMIM number 139400), colour blindness (gene location Xq28, OMIM number 303800) and ear without Darwinian notch. Further, an additional 5 HRC on human arms were evaluated as well: distal or proximal hyperextensibility of the thumb, index finger longer than the ring finger (OMIM number 136100), left-handedness (gene location 2p12q22, OMIM number 139900), right thumb over left thumb (hand clasping) (OMIM number 139800) and top joint of the thumb $>45^{\circ}$ (OMIM) [17].

\section{Statistical analysis}

To present the frequency of evaluated HRC in the groups of individuals with normal weight, overweight and obese individuals we used whole numbers and percentages. The degree of genetic homozygosity for each group was presented as the mean value (MV) with standard deviation (SD). Chi squared test $\left(\chi^{2}\right)$ was used to compare frequencies of HRC between evaluated groups. Comparison of mean values of HRC between two groups was done by Student's t-test, while unifactorial ANOVA ( $f$ values) was used to compare mean values of HRC between 3 groups of individuals. Statistical significance was set at $p<0.05$.

\section{Results}

From 440 individuals, 300 (68.2\%) had normal weight, 100 (22.7\%) were overweight and 40 (9.1\%) were obese. 


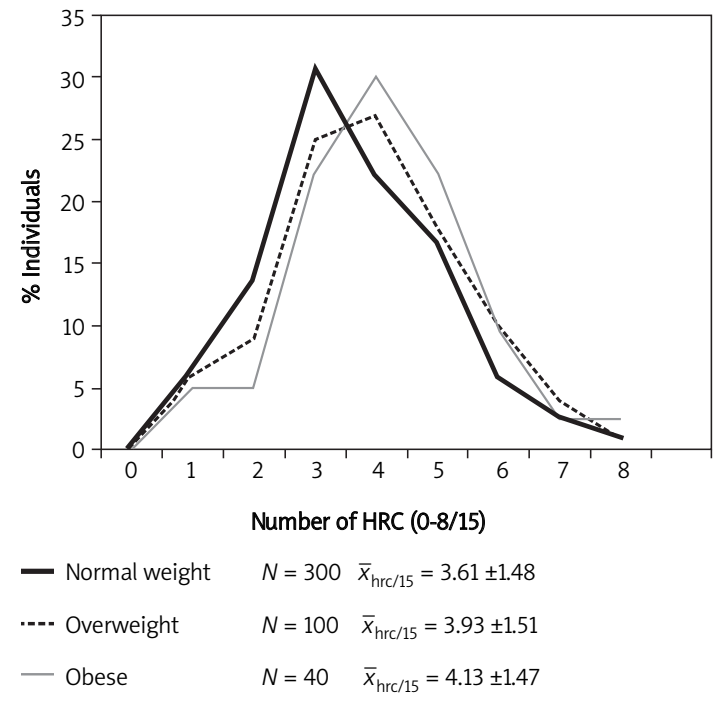

Figure 1. Frequencies of homozygous recessive characteristics (HRC) in normal weight, overweight and obese group

Table I. Statistical presentation of homozygous recessive characteristics (HRC) mean values in normal weight, overweight and obese groups

\begin{tabular}{|lcc|}
\hline Parameter & Values of $t$ & Values of $f$ \\
\hline $\begin{array}{l}\text { Normal weight/ } \\
\text { overweight/obese }\end{array}$ & $3.33^{*}$ \\
\hline Normal weight/overweight & 1.86 \\
\hline Normal weight/obese & $2.09^{\star}$ \\
\hline Overweight/obese & 0.71 \\
\hline${ }^{*} p<0.05$ & \\
\hline
\end{tabular}

Comparing mean values of HRC between groups of participants, it was found that there is no significant difference in the presence of HRC between groups of individuals with normal weight and those who were overweight (normal weight: $3.61 \pm 1.48$; overweight: $3.93 \pm 1.51$; $t_{\text {normal } \text { weight } / \text { overweight }}=1.86$; $p>0.05)$ and groups of individuals who were overweight and obese (overweight: $3.93 \pm 1.51$; obese: $4.13 \pm 1.47$; $\mathrm{t}_{\text {overweight/obese }}=0.71 ; p>0.05$ ), while there was a significant difference between groups of individuals with normal weight and those who were obese (normal weight: $3.61 \pm 1.48$; obese: 4.13 \pm 1.47 ; $t_{\text {normal weight/obese }}=2.09 ; p<0.05$ ) (Figure 1 , Table I). The distribution of homozygous recessive characteristics (HRC) in evaluated groups of individuals is presented in Table I.

Statistical analysis of HRC in normal weight and overweight individuals is presented in Table II. Our results indicate that there are differences in the distribution of individual HRC between these two groups. It was noted that 2 recessive traits were significantly more frequent in the group of overweight participants and 2 other recessive traits were significantly more frequent in the group with normal weight (Tables II and III). The type of individual variation in the two studied groups significantly differed $\left(\Sigma \chi^{2}=55.8, \mathrm{~d} f=14, p<0.01\right)$.

Regarding the participants with normal weight and those who were obese, the results of the HRC test indicate that there are differences in the distribution of individual HRC between these two groups. It was noted that 3 recessive traits were significantly more frequent in the group of obese participants (Tables II and III) while one recessive trait

Table II. Distribution of homozygous recessive characteristics (HRC) in normal weight, overweight and obese groups

\begin{tabular}{|lccc|}
\hline HRC & Normal weight & Overweight & Obese \\
& $N=300, n(\%)$ & $N=40, n(\%)$ & $15(37.5)$ \\
\hline Blond hair & $51(17.0)$ & $39(39.0)$ & $20(50.0)$ \\
\hline Straight hair & $148(49.3)$ & $56(56.0)$ & $3(7.5)$ \\
\hline Two hair whorls & $29(9.7)$ & $8(8.0)$ & $5(12.5)$ \\
\hline Opposite hair whorl orientation & $43(14.3)$ & $10(10.0)$ & $18(45.0)$ \\
\hline Soft hair & $118(39.3)$ & $46(46.0)$ & $16(40.0)$ \\
\hline Continuous hairline & $105(35.0)$ & $40(40.0)$ & $5(12.5)$ \\
\hline Attached ear lobe & $67(22.3)$ & $11(11.0)$ & $2(5.0)$ \\
\hline Ear without Darwinian notch & $23(7.7)$ & $1(1.0)$ & $12(30.0)$ \\
\hline Blue eyes & $68(22.7)$ & $30(30.0)$ & $1(2.5)$ \\
\hline Colour blindness & $11(3.7)$ & $2(2.0)$ & $16(40.0)$ \\
\hline Right thumb over left thumb & $134(44.7)$ & $38(38.0)$ & $14(35.0)$ \\
\hline Top joint of the thumb $>45^{\circ}$ & $94(31.3)$ & $37(37.0)$ & $12(30.3)$ \\
\hline Proximal thumb extensibility & $40(13.3)$ & $22(22.0)$ & $12(30.0)$ \\
\hline Left-handedness & $41(13.7)$ & $18(18.0)$ & $14(35.0)$ \\
\hline Index finger longer than the ring finger & $110(36.7)$ & $35(35.0)$ & \\
\hline
\end{tabular}


Table III. Statistical presentation of homozygous recessive characteristics (HRC) distribution in normal weight, overweight and obese groups

\begin{tabular}{|c|c|c|c|}
\hline $\operatorname{HRC}\left(\alpha^{2}\right)$ & $\begin{array}{c}\text { Normal weight/ } \\
\text { overweight }\end{array}$ & $\begin{array}{l}\text { Normal weight/ } \\
\text { obese }\end{array}$ & Overweight/obese \\
\hline Blond hair & $28.5^{\star *}$ & $24.7^{\star \star}$ & 0.1 \\
\hline Straight hair & 0.9 & 0.0 & 0.7 \\
\hline Two hair whorls & 0.3 & 0.5 & 0.0 \\
\hline Opposite hair whorl orientation & 1.3 & 0.2 & 0.6 \\
\hline Soft hair & 1.1 & 0.8 & 0.0 \\
\hline Continuous hairline & 0.7 & 0.7 & 0.0 \\
\hline Attached ear lobe & $5.7^{*}$ & $4.3^{*}$ & 0.2 \\
\hline Ear without Darwinian notch & $5.8^{*}$ & 0.9 & $9.6^{* *}$ \\
\hline Blue eyes & 2.3 & 2.3 & 0.0 \\
\hline Colour blindness & 0.1 & 0.4 & 0.1 \\
\hline Right thumb over left thumb & 1.0 & 0.5 & 0.1 \\
\hline Top joint of the thumb $>45^{\circ}$ & 1.0 & 0.4 & 0.1 \\
\hline Proximal thumb extensibility & $5.7^{*}$ & $21.7^{\star \star}$ & 2.7 \\
\hline Left-handedness & 1.3 & $19.4^{\star *}$ & $6.4^{*}$ \\
\hline Index finger longer than the ring finger & 0.1 & 0.1 & 0.0 \\
\hline$\Sigma \chi^{2}$ & $55.8^{\star *}$ & $76.9^{\star *}$ & 20.6 \\
\hline
\end{tabular}

${ }^{*} p<0.05,{ }^{* *} p<0.01$

was significantly more frequent in the group with normal weight. The type of individual variation in the two studied groups significantly differed $\left(\Sigma \chi^{2}=76.9, \mathrm{~d} f=14, p<0.01\right)$.

When comparing the group with overweight participants and the group with obese participants, the results of the HRC test indicate that there are differences in the distribution of individual HRC between these two groups. It was noted that 2 recessive traits were significantly more frequent in the group of obese participants (Tables II and III). The type of individual variation in the two studied groups did not significantly differ $\left(\Sigma \chi^{2}=20.6\right.$, $\mathrm{d} f=14, p>0.05)$.

\section{Discussion}

The findings of our study on the population genetic approach for the first time clearly show that there is morpho-physiological difference between samples of individuals for the predisposition regarding obesity.

We have demonstrated that increased BMI and therefore overweight or obesity is in correlation with increased genetic homozygosity, indicating increased genetic loads for individuals with higher BMI values. The present statistically significant increase of recessive homozygosity for obese participants versus those with normal weight could give us an impression that such increase of genetic loads could bring the organism into a more specific physiological condition for susceptibility to fat mass increase and therefore being obese [18, 19]. Although we found an increase in genetic homozygosity for overweight individuals versus normal weight individuals and for obese participants versus overweight participants, such elevation in genetic homozygosity was not statistically significant. A possible explanation for this observation could be that obesity versus overweight has increased genetic predisposition and that some preferential phenotypes exist.

Significantly increased genetic homozygosity in obese individuals could bring the organism into a specific state of genetic-physiological homeostasis, enabling easier expression of a predisposition to obesity. Furthermore, higher genetic homozygosity could result in pleiotropic effects of specific genes responsible for expressing a predisposition to obesity.

The evaluated phenotype traits, at a population genetic level, indicate the intrinsic changes in samples of individuals with normal weight, those with overweight and those who are obese.

The presence of variability in the proportion of certain observed recessive phenotype traits between different samples of individuals has been studied previously (e.g., between genders, between ill and healthy individuals, between sportsmen and non-sportsmen) [14, 19-21]. In our study, we observed that different traits significantly differed between evaluated groups, as well as a different proportion of traits, giving us the assumption of dif- 
ferent predisposition to overweight and obesity states. It should also be stressed that analysis of individual traits distribution implies the presence of different presentation of characteristic groups of traits between evaluated samples of individuals, pointing to the possibility of a correlation with different combinations of polygenes that could be involved in regulatory processes that are responsible for fat metabolism, resulting in the increase of BMI. However, absence of statistical significance between overweight and obese samples of individuals regarding the degree of genetic homozygosity and individual variation of evaluated traits indicates that these individuals are more similar in the population genetic approach versus those with normal weight.

In this study there were a few limitations. The first one applies to the variations of normal genotype in the human population, since we cannot establish it with exact confidence. Also, the evaluated phenotype characteristics should be improved further with other morphophysiological characteristics.

From the results of our study it can be concluded that overweight and obese individuals have a genetic predisposition, and that different expression of genetic loads could be one of the possible explanations for different susceptibility to the increase of fat mass and BMI.

Such evaluation of homozygously recessive characteristics in a population with increased body mass could be of some benefit as a potential screening method along with other diagnostic approaches that might identify the population at risk, enabling timely introduction of prophylactic measures.

\section{References}

1. Franks PW, Ling C. Epigenetics and obesity: the devil is in the details. BMC Med 2010; 8: 88.

2. Loos RJ, Lindgren CM, Li S, et al. Common variants near MC4R are associated with fat mass, weight and risk of obesity. Nat Genet 2008; 40: 768-75.

3. Sallis JF. Age-related decline in physical activity: a synthesis of human and animal studies. Med Sci Sport Exerc 2000; 32: 1598-600.

4. Simeunovic S, Milincic Z, Nikolic D, et al. Physical activity evaluation in Yugoslav study of atherosclerosis precursors in school children - YUSAD Study. Arch Med Sci 2010; 6: 874-8.

5. Jermendy A, Korner A, Kovacs $M$, et al. Association between toll-like receptor polymorphisms and serum levels of tumor necrosis factor-alpha and its soluble receptors in obese children. Med Sci Monit 2010; 16: CR180-5.

6. Telles S, Naveen V, Balkrishna A, Kumar S. Short term health impact of a yoga and diet change program on obesity. Med Sci Monit 2010; 16: CR35-40.

7. Metz U, Welke J, Esch T, Renneberg B, Braun V, Heintze C. Perception of stress and quality of life in overweight and obese people - Implications for preventive consultancies in primary care. Med Sci Monit 2009; 15: PH1-6.
8. Wang QM, Cai Y, Tian DR, et al. Peroxiredoxin1: a potential obesity-related factor in the hypothalamus. Med Sci Monit 2010; 16: BR321-6.

9. Cvjeticanin S, Marinkovic D. Genetic variability and frequencies of $\mathrm{ABO}$ blood types among different samples of patients from Serbia. Korean J Genetics 2005; 27: 35-40.

10. Nikolic D, Cvjeticanin S, Petronic I, et al. Degree of genetic homozygosity and distribution of $\mathrm{ABO}$ blood types among patients with spina bifida occulta and spina bifida apperta. Arch Med Sci 2010; 6: 854-9.

11. Must A, Dallal GE, Dietz WH. Reference data for obesity: 85th and 95th percentiles of body mass index (wt/ht2) and triceps skinfold thickness. Am J Clin Nutr 1991; 53: 839-46.

12. Marinkovic D, Ilic M, Spremo B. Studies of human population - genetic variation. Comparison of homozygously recessive traits in attendants of special and regular schools in Serbia. Arch Biol Nauka 1990; 42: 11-2.

13. Pesut D. Susceptibility to lung tuberculosis - a population genetic study. Med Pregl 2004; 57: 21-4.

14. Cvjeticanin S, Marinkovic D. Genetic variability in the group of patients with congenital hip dislocation. Genetika 2005; 41: 1142-6.

15. Marinkovic D, Cvjeticanin S. Population-genetic study of Balkan endemic nephrophaty in Serbia. Genetika 2007; 43: 1134-8.

16. Marinkovic D, Cvjeticanin S, Stanojevic M. Population genetic analyses of susceptibility to developing alcohol dependence. Addiction Research and Theory 2008; 16: 331-7.

17. Online Mendelian inheritance in man (OMIM) http://www. ncbi.nlm.nih.gov

18. Marinkovic D, Jovanovic D, Cvjeticanin S, Savic M, Brankovic S. Genetic homozygosity and normal vs. pathological human variation. Genetika 1994; 26: 147-56.

19. Cvjeticanin S, Marinkovic D. Morphogenetic variability during selection of elite water polo players. J Sports Sci 2009; 27: 941-7.

20. Ziering C, Krenitsky G. The Ziering whorl classification of scalp hair. Dermatol Surg 2003; 29: 817-21.

21. Gillam L, McDonald R, Ebling FJ, Mayhew TM. Human 2D (index) and 4D (ring) finger lengths and ratios: crosssectional data on linear growth patterns, sexual dimorphism and lateral asymmetry from 4 to 60 years of age. J Anat 2008; 213: 325-35. 